\title{
GC-MS ANALYSIS OF THE FATTY ACIDS METHYL ESTERS IN JAPANESE QUAIL FAT
}

\author{
Ion Dragalin ${ }^{a^{*}}$, Olga Morarescu ${ }^{a}$, Maria Sedcenco ${ }^{b}$, Radu Marin Rosca ${ }^{b}$ \\ ${ }^{a}$ Institute of Chemistry of Academy of Science of Moldova, 3, Academiei str. Chisinau MD-2028, Republic of Moldova \\ bî.I. "Antoni Cristina", 2A, Stefan cel Mare str., Gratiesti MD-2093, Republic of Moldova \\ *e-mail: iondragalin@yahoo.com; phone: (+373 22) 739769
}

\begin{abstract}
The accumulated waste fat as production from Faraon quail breeds has been investigated for the first time by using GC-MS technique, preventively converting it via methanolysis to fatty acid methyl esters. The test results, regarding the content of unsaturated fatty acids having a favorable to human body cis-configuration (77.8\%), confirm their nutritional value and the possibility of using this fat in cosmetic, pharmaceutical and food industries.
\end{abstract}

Keywords: fatty acid methyl esters, GC-MS analysis, linoleic acid (Z,Z), oleic acid (Z), Japanese quail fat.

Received: June 2015/ Revised final: September 2015/ Accepted: September 2015

\section{Introduction}

The value and chemical composition of quail meat, which contains monounsaturated fatty acids at the amount of about $50 \%$, polyunsaturated acids at the amount of $15 \%$, and trans-configured acids at the amount of $3 \%$ is known [1]. The unique composition of quail carcass products determines their nutritional and healing qualities. The antimicrobial activity of fatty acids and their esters against pathogenic microorganisms in the oral cavity is renowned [2]. In Republic of Moldova there are six individual companies that cultivate quails. We have analyzed the accumulated fat at "Antoni Cristina" company, collected from quail carcasses as waste, applying the most efficient method of GC-MS [3], to study whether the quail fat could be used as the raw material for manufacturing solid soap.

This investigation was aimed at pioneering analysis of the fatty acids of the Japanese quail fat accumulated as production waste, for new applications in cosmetics, pharmaceuticals or food industry.

\section{Experimental}

The research materials were collected from the poultry of Faraon breed at the age of 60 days and included the grease surrounding their entrails. The nutritional priorities, chemical composition, and production advantages of Faraon breed are described $[4,5]$. For the analysis, the fat was subjected to the catalyzed by potassium hydroxide transesterification by methanolysis, according to the previously described by us methodology [6]. Control of the progress of the methanolysis reaction was performed on Sorbfil silicagel thin-layer plates by eluting the components with an EtOAc-Hexane mixture of solvents (1:5.7).

The analysis of the obtained by methanolysis fatty acids methyl esters was performed by using the GC-MS system Agilent Technologies 7890A with 5975C Mass-Selective Detector(GC-MSD) equipped with split-splitless injector (split, $250^{\circ} \mathrm{C}$, split ratio $\left.1: 50,1 \mu \mathrm{L}\right)$ and HP-5ms capillary calibrated column $(30 \mathrm{~m} \times 0.5 \mathrm{~mm}, 0.25 \mu \mathrm{m})$; Carrier: Helium $1.1 \mathrm{~mL} / \mathrm{min}$; Oven: $60{ }^{\circ} \mathrm{C}-5 \mathrm{~min}, 15{ }^{\circ} \mathrm{C} / \mathrm{min}-300{ }^{\circ} \mathrm{C}-10 \mathrm{~min}$; MSD in scan 30-300, $15 \mathrm{~min}, 30-550 \mathrm{amu}$, solvent delay $3 \mathrm{~min}$.

For transesterification fat ( $3.176 \mathrm{~g}$ ) was placed into a glass flask equipped with a cooler, and a solution of 0.102 $\mathrm{g}$ of $\mathrm{KOH}$ in $1 \mathrm{~mL}$ of $\mathrm{MeOH}$ (anh.) was added; the resulting mixture was continuously stirred for 3 hours at $40^{\circ} \mathrm{C}$ on a magnetic Hotplate Stirrer. After cooling $50 \mathrm{~mL}$ of $\mathrm{Et}_{2} \mathrm{O}$ was added and the mixture was neutralized with an aqueous solution of $10 \% \mathrm{H}_{2} \mathrm{SO}_{4}$. The ether extract of fatty acid methyl ethers was rinsed with distilled water to neutral medium and then dried by using anhydrous $\mathrm{Na}_{2} \mathrm{SO}_{4}$.

\section{Results and discussion}

GC-MS analysis of the methyl esters derived from quail fat has demonstrated the presence of 35 organic components in the reaction product (chromatogram, Figure 1), from which the following have been identified by comparison with the mass spectra from the device database (Figures 2 and 3), which constitute $98.97 \%$ of total mass (Table 1).

Analysis of the obtained results (Table 2) that are compared with the literary data, regarding the composition and the ratio of fatty acids of meat from 35-days-old Japanese quails [4], demonstrates a higher content of unsaturated acids with cis- (Z) configuration representing $77.8 \%$. The SFA/UFA (saturated fatty acids/unsaturated fatty acids) ratio amounts to $0.27: 1$ for fat, as compared to $0.52: 1$ for quail meat. The SFA/PUFA (saturated fatty acids/ polyunsaturated fatty acids) ratio obtained for quail fat is $1.6: 1$, as compared to $0.73: 1$ for meat. The absence of Omega- 3 acids should be 
mentioned: only some traces of alpha-linolenic acid have been detected in quail fat. These results demonstrate nutritive and curative properties of quail fat.

On the basis of the obtained results an inventory patent application has been registered, regarding the preparation of high-quality soap [7].

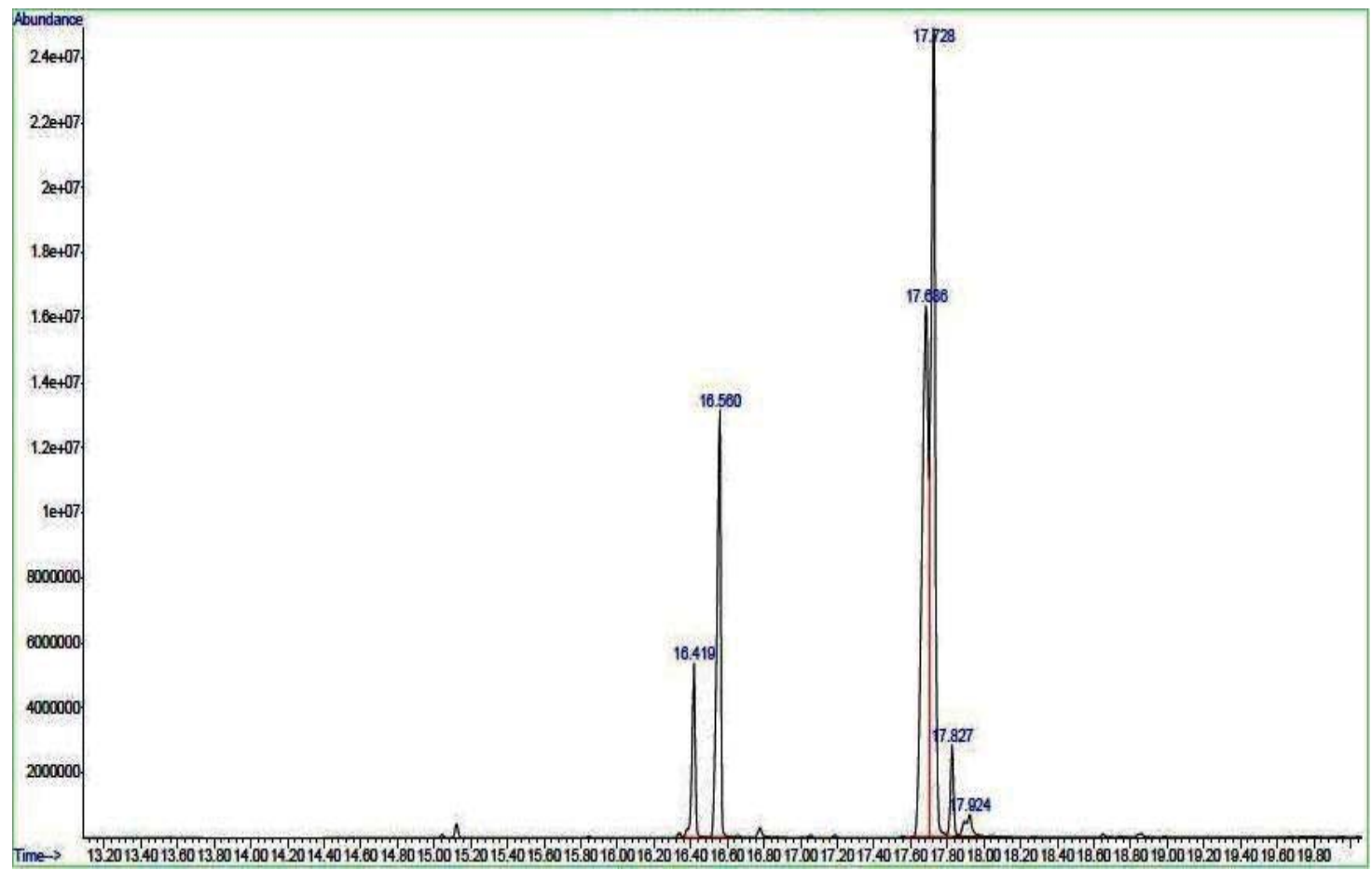

Figure 1. Chromatogram of the reaction product.

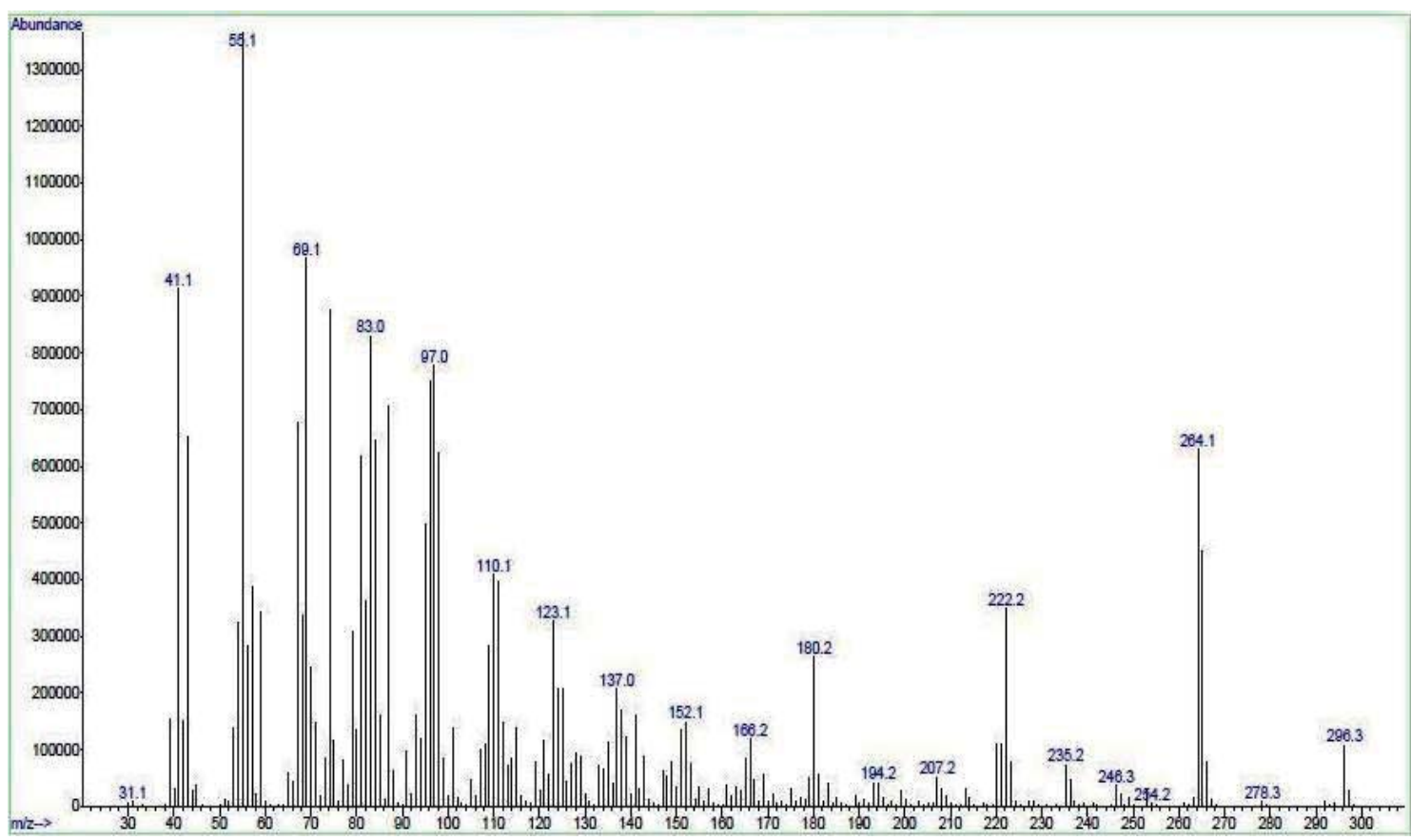

Figure 2. Mass-spectrum of major component of the reaction product, 9-octadecenoic acid, methyl ester, (Z)-. 


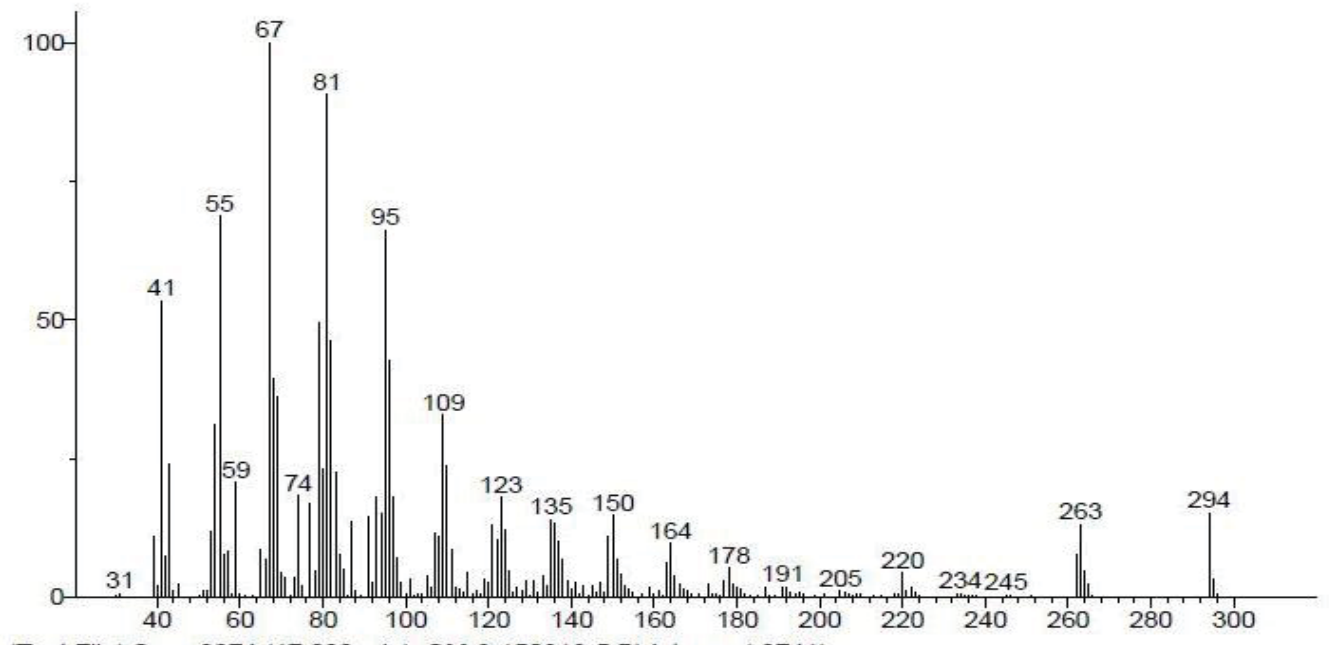

(Text File) Scan 3974 (17.688 min): OM-3-150313-5.Dldata.ms (-3741)
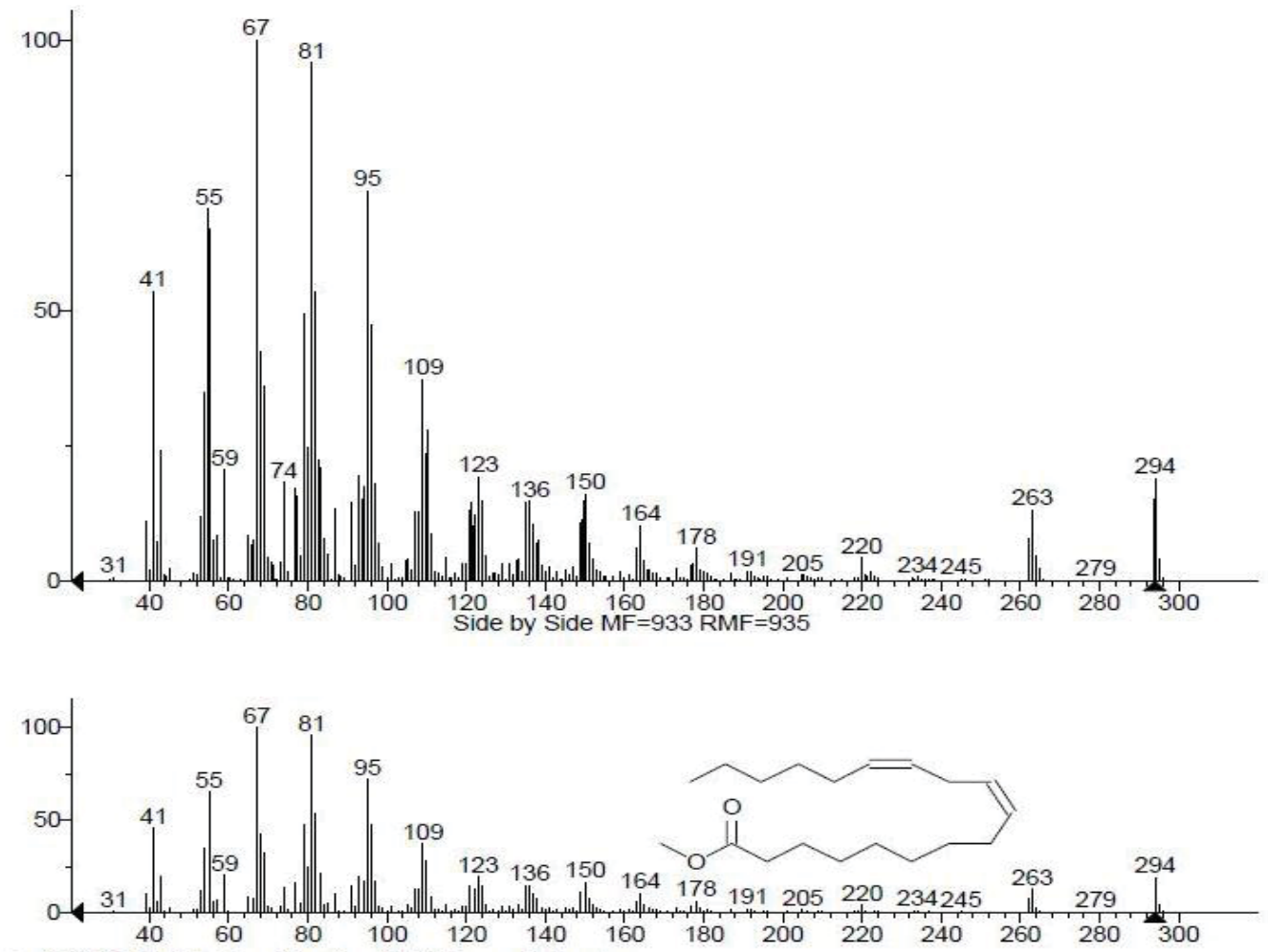

(mainlib) 9,12-Octadecadienoic acid (Z,Z)-, methyl ester

Figure 3. Mass-spectra of linoleic-(Z,Z) acid, methyl ester.

The results of GC-MS analysis of the methyl esters of fatty acids

Table 1 (\% from total mass).

\begin{tabular}{cccc}
\hline No. & Rt, $\min$ & Components of analysis & $\%$ \\
\hline 1 & 15.045 & Methyl myristoleate & 0.10 \\
2 & 15.124 & Methyl tetradecanoate & 0.42 \\
3 & 15.845 & Pentadecanoic acid, methyl ester & 0.05 \\
4 & 16.339 & Methyl 7,10-hexadecadienoate & 0.15 \\
5 & 16.419 & 9-Hexadecenoic acid (Z), methyl ester & 5.82 \\
6 & 16.559 & n-Hexadecanoic acid methyl ester & 16.85 \\
\hline
\end{tabular}




\begin{tabular}{cccc}
\hline & $R t, \min$ & Components of analysis & $\%$ \\
\hline 7 & 16.779 & n-Hexadecanoic acid & 0.46 \\
8 & 17.686 & $9,12-$ Octadecadienoic acid(Z,Z) methyl ester & 33.05 \\
9 & 17.727 & 9- Octadecenoic acid(Z), methyl ester & 36.78 \\
10 & 17.828 & Octadecanoic acid, methyl ester & 3.00 \\
11 & 17.923 & Cis-13- Octadecenoic acid & 1.92 \\
12 & 18.859 & Cis-11- Eicosenoic acid methyl ester & 0.23 \\
13 & 18.652 & Arachidonic acid & 0.14 \\
\hline
\end{tabular}

Fatty acids content of fat from Faraon breed of Japanese Quails.

\begin{tabular}{cll}
\hline Carbon chain & \multicolumn{1}{c}{ Fatty acids } & \% from total lipids \\
\hline $14: 0$ & Miristic & 0.42 \\
$14: 1$ & Miristoleic & 0.10 \\
$15: 0$ & Pentadecanoic & 0.05 \\
$16: 0$ & Palmitic & 17.31 \\
$16: 1$ & Palmitoleic & 5.82 \\
$16: 2$ & $7,10-$-Hexadecadienoic & 0.15 \\
$18: 0$ & Stearic & 3.00 \\
$18: 1$ & Oleic(Z) & 36.78 \\
$18: 1$ & Cis-13-Octadecenoic & 1.92 \\
$18: 2$ & Linoleic(Z,Z), Omega-6 & 33.05 \\
$20: 1$ & Cis-11- Eicosenoic & 0.23 \\
$20: 4$ & Arachidonic, Omega-6 & 0.14 \\
& Total Saturated fatty acids (SFA) & 20.78 \\
& Total Unsaturated fatty acids (UFA) & 78.19 \\
& Total Monounsaturated fatty acids (MUFA) & 44.85 \\
& Total Polyunsaturated fatty acids (PUFA) & 33.34 \\
& Ratio : SFA / UFA & $0.27: 1$ \\
& Ratio : PUFA / SFA & $1.60: 1$ \\
\hline
\end{tabular}

\section{Conclusions}

Analysis of fatty acid methyl esters using a GC-MS high-performance system has demonstrated a high content (77.8\%) of Z-configuration acids, in particular, oleic Z (18:1), linoleic-Z,Z (18:2), and palmitoleic-Z (16:1), which confirm the curative and nutritional value of Faraon quail fat and the possibility of its use in cosmetic, pharmaceutical and food industries.

Investigation of the collected Faraon quail fat as production waste has allowed its capitalization by manufacturing high-quality soap that was registered as inventory patent application (Patent MD, No. 932).

\section{References}

1. Gecgel, U.; Yilmaz, I.; Gurcan, E.K.; Karasu, S.; Dulger, G.C. Comparison of fatty acid composition between female and male japanese quail meats. Journal of Chemistry, 2015, Vol. 2015, 8 p., doi:10.1155/2015/569746.

2. El-Dengawy, R.A.; Nassar, A.M. Investigation on the nutritive value and microbiological quality of wild quail carcasses. Nahrung/Food, 2001, 45, pp. 50-54.

3. Seppanen-Laakso, T.; Laakso, I.; Hiltunen, R. Analysis of fatty acids by gas chromatography and its relevance to research on health and nutrition. Analytica Chemica Acta, 2002, 465, pp. 39-62.

4. Gencev, A.; Mihaylova, G.; Ribarski, S.; Pavlov, A.; Kabakchiev, M. Meat quality and composition in Japanese Quails. Trakia Journal of Sciences, 2008, 6, pp. 72-82.

5. Gencev, A.G.; Ribarski, S.S.; Afanasjev, G.D.; Blohin, G.I. Fattening capacities and meat quality of Japanese quails of Faraon and White English breeds. Journal Central European of Agriculture, 2005, 6, pp. 495-500.

6. Lupascu, T.; Dragalin, I.; Vlad, P.; Serban, S.; Stepan, E. Process for preparing the mixture of methyl esters of fatty acids from fats, Biodiesel. MD Patent, 2004, No. 2382 (in Romanian).

7. Rosca, R.M.; Rosca, V.; Sadcenco, M. Toilet soap. MD Patent, 2015, No. 932 (in Romanian). 